\title{
Guerrero. La representación política de los pueblos indígenas mediante las circunscripciones electorales
}

\section{Guerrero. The political representation of indigenous peoples through electoral districts}

Celia Palacios Mora*

Leticia Gerónimo Mendoza**

\section{Resumen}

La dinámica demográfica de México requiere la periódica delimitación de sus territorios electorales, buscando el equilibrio poblacional, pero también la representación de los grupos indigenas, que constituyen un importante sector sociocultural.

Este artículo esquematiza la metodología empleada para agrupar los municipios indígenas del estado de Guerrero para la demarcación distrital, la cual considera su forma, la distribución en el territorio, la población total y la proporción de población indígena, así como los grupos etnolingüisticos mayoritarios; se diseñó para ser aplicada a cualquier entidad federativa. Busca preservar la identidad indigena mediante la representación de diputados de mayoría relativa en los distritos electorales tanto federales como locales.

Palabras clave: distritación; circunscripciones uninominales; indígenas; grupo etnolingüístico.

\footnotetext{
Abstract

The demographic dynamics of Mexico requires the periodic delimitation of its electoral territories, in an attempt to achieve population balance, but also the representation of the indigenous groups who constitute an important sociocultural sector.

This article outlines the methodology used to group together the indigenous municipalities of the state of Guerrero for the demarcation of districts, considers

* Universidad Nacional Autónoma de México. Posgrado en Geografía. Dirección postal: Edificio E, primer nivel, Circuito de Posgrados, Ciudad Universitaria, 04510, Ciudad de México, México. Correo electrónico: celia6619@yahoo.com.mx

** Investigadora independiente. México. Correo electrónico: leticiagermen@yahoo.com.mx 
their form and distribution in the territory, the total population and proportion of indigenous population, as well as major ethnolinguistic groups. It was designed to be used in any state. It seeks to preserve indigenous identity through the representation of deputies with a relative majority in federal and local electoral districts.

Keywords: delimiting districts; single-candidate systems; indigenous ethnolinguistic group.

\section{Introducción}

La distritación es el proceso mediante el cual se trazan los límites geográficos con fines electorales, los cuales permiten identificar las áreas en las que los ciudadanos ejercen el voto para elegir al o a los representantes políticos de su nación (Baños, 2014, p. 82). Debe ser periódica debido al constante movimiento de la población, lo cual genera desequilibrio demográfico en las entidades federativas y los distritos electorales.

En México, para el ámbito federal, el artículo 53 constitucional señala que la demarcación de los 300 distritos electorales uninominales se hará con la población total del país y teniendo en cuenta el último censo general de población. En el caso de los distritos locales, la constitución estatal correspondiente indica el número de circunscripciones uninominales en que deberá dividirse el territorio de cada entidad federativa.

Previo a un proceso de distritación se definen los criterios, así como las reglas que deberán aplicarse. Se determinan a partir de dos normas prioritarias. La primera es la referente a las leyes, una de las cuales es el mandato constitucional que señala la igualdad de la población; la legislación también mandata lo relativo a la población indígena en el Artículo Tercero Transitorio de la Constitución Política de los Estados Unidos Mexicanos. ${ }^{1}$ La segunda norma incluye aspectos técnico-operativos como la contigüidad, las fronteras político-administrativas, la compacidad y las comunidades de interés.

El presente artículo recopila parte de los resultados de la investigación desarrollada en el Comité Técnico para el Seguimiento y Evaluación de los Trabajos de Distritación, que asesoró al Consejo General del Instituto Nacional Electoral (INE) en el periodo 2015-2017 para la incorporación del criterio etnolingüístico en el ejercicio de distritación local en el estado de

${ }^{1}$ Artículo Tercero Transitorio. Para establecer la demarcación territorial de los distritos electorales uninominales deberá tomarse en consideración, cuando sea factible, la ubicación de los pueblos y comunidades indígenas, a fin de propiciar su participación política. Diario Oficial de la Federación, 14 de agosto de 2001. 
Guerrero. Específicamente se presenta la metodología diseñada para dar cumplimiento al criterio 3 del Acuerdo INE/CG195/2015.

Con base en dicho criterio, se desarrolló una metodología para clasificar y formar conjuntos de municipios mediante una tipificación basada en las características señaladas por la Comisión Nacional para el Desarrollo de los Pueblos Indígenas (CDI): forma de cada uno de éstos, ubicación, vecindad, población total, porcentaje de población indígena y lengua predominante.

Esta metodología se utilizó para el ejercicio de distritación federal y permitió tipificar los municipios de 16 entidades federativas con significativa presencia de población indígena: Campeche, Chiapas, Chihuahua, Durango, Guerrero, Hidalgo, Jalisco, México, Michoacán, Nayarit, Oaxaca, Puebla, Quintana Roo, San Luis Potosí, Veracruz y Yucatán; también se utilizó para ocho entidades federativas en la distritación local: Campeche, Chiapas, Guerrero, Jalisco, México, Michoacán, San Luis Potosí y Yucatán. En total, dicha metodología se empleó en la delimitación distrital de 24 entidades federativas.

El presente documento se integra de cuatro apartados: en el primero se da una breve explicación sobre la población indígena y su distribución general en el país; el segundo introduce los criterios de distritación y su aplicación, y señala la importancia de la población indígena en éstos; el tercer apartado describe la metodología que debe seguirse para la agrupación de los municipios indígenas en las distritaciones; y finalmente el cuarto apartado describe la aplicación detallada de la metodología para los municipios indígenas de Guerrero con base en su lengua predominante.

\section{La población indígena de México}

La Constitución Política de los Estados Unidos Mexicanos en su artículo 2o señala:

La nación tiene una composición pluricultural sustentada originalmente por sus pueblos indígenas, que son aquellos que descienden de poblaciones que habitaban en el territorio actual del país al iniciarse la colonización y que conservan sus propias instituciones sociales, económicas, culturales y políticas. Resalta que la conciencia de su identidad indígena deberá ser criterio fundamental para determinar a quiénes se aplican las disposiciones sobre pueblos indígenas. Son comunidades indígenas integrantes de un pueblo indígena, aquellas que forman una unidad social, económica y cultural, que están asentadas en un territorio y que reconocen autoridades propias de acuerdo con sus usos y costumbres. 
A partir del reconocimiento constitucional, la población indígena se identifica mediante la lengua, que a su vez constituye una de las características que distingue a un grupo de población. De acuerdo con la CDI, en el año 2010, en México la población en hogares cuyo jefe de familia era hablante de lengua indígena fue de 11.13 millones de personas. ${ }^{2}$ La institución también considera que con el uso del criterio "hogar" se trasciende una concepción del desarrollo que supone sólo factores económicos como los únicos determinantes, para complementar una concepción sistémica, más integral, que comprende a la red de relaciones entre ancestros-descendientes y permite considerar no sólo a los individuos, sino a los otros niveles de complejidad en esa red de relaciones: familias, comunidades, municipios, regiones, etc. Con este criterio se incorpora en la población indígena al universo de personas que, aun no siendo hablantes de lengua indígena, comparten modos de vida y relaciones activas en el marco de las identidades étnicas (CDI, 2017).

La CDI clasifica los municipios a partir del número total de habitantes y la proporción de población indígena residente; con estos datos define a los municipios indígenas como aquellos con $40 \%$ o más de población indígena.

La población en hogares indígenas es minoría a escala nacional: en 2010 representó poco más del 10\% de la población total. Sin embargo, en escala estatal observa valores significativos, ya que en Campeche, Chiapas, Guerrero, Hidalgo, Oaxaca, Puebla, Quintana Roo y Yucatán llega a representar hasta el $50 \%$ de la población total; estas ocho entidades concentran, según datos del censo de 2010 , poco más de siete millones de hablantes de lengua indígena, esto es, el $63 \%$ de la población indígena del país.

Por otra parte, se observa que casi el $60 \%$ de la población indígena vive en los municipios con más del $40 \%$ de habitantes indígenas con respecto al total municipal, mientras que poco más del $40 \%$ restante habita en municipios donde su representación proporcional con respecto a la población total es minoritaria (cálculos con base en CDI, 2010). Esta población se distribuye en todo el territorio nacional, y habita tanto en grandes ciudades como en pequeñas localidades rurales con escasa accesibilidad. En las zonas metropolitanas del país presenta disgregación, lo que impide considerarla en unidades geográficas definidas en el interior de las manchas urbanas.

${ }^{2}$ La CDI considera como población indígena a todas las personas que forman parte de un hogar indígena, es decir, donde el jefe/a del hogar, su cónyuge y/o alguno de los ascendientes (madre o padre, madrastra o padrastro, abuelo/a, bisabuelo/a, tatarabuelo/a, suegro/a declaró ser hablante de lengua indígena. Además, también incluye a personas que declararon hablar alguna lengua indígena y que no forman parte de estos hogares. 
Otra característica de la población indígena de México es que cuenta con una diversidad etnolingüística de 66 grupos. Algunas de estas lenguas tienen gran número de hablantes, como el náhuatl, con más de 2.5 millones, en contraste con el ayapaneco, que cuenta con menos de 100 hablantes (CDI, 2010). Los grupos lingüísticos también están mezclados geográficamente, de tal manera que tanto en las grandes ciudades como en las localidades rurales encontramos hablantes de diferentes lenguas y, por lo tanto, pertenecientes a diferentes grupos etnolingüísticos, lo cual impide conformar regiones homogéneas y contiguas. El Mapa 1 muestra la distribución de la población indígena de acuerdo con la lengua predominante por localidad en el estado de Guerrero. Destaca por una parte la dispersión geográfica de los hablantes de las diferentes lenguas, y por otra, la mezcla de dos o más grupos etnolingüísticos que conviven en un mismo espacio geográfico.

El carácter etnolingüístico fue uno de los principales criterios para la distritación; éste, en conjunto con los que se explican en el siguiente apartado, constituyeron la base para la demarcación de circunscripciones electorales.

\section{Criterios de distritación}

El proceso de distritación consiste en el desarrollo de metodologías, modelos matemáticos y sistemas informáticos que permiten la división del territorio de cada una de las entidades federativas del país en regiones homogéneas en cuanto a población, integridad político-administrativa y, en su caso, características socioeconómicas (que se consideran rasgos geográficos que pueden dificultar la funcionalidad del territorio del distrito a conformar). Para el caso de la distritación electoral 2015-2017, un aspecto fundamental es el correspondiente a la población indígena que, junto con el equilibrio poblacional, constituye un criterio con mandato constitucional.

Cabe mencionar que hubo variaciones en los criterios para las distritaciones federal y locales. Primero se definieron los criterios para las locales, en las que se incorporó a los municipios con más de $40 \%$ de población indígena para procurar la conformación de distritos indígenas, es decir, agrupaciones de municipios cuya suma de población indígena sea de $40 \%$ o más. En los criterios para la distritación federal se agregó la lengua predominante; el objetivo fue demarcar distritos cuya suma de población indígena sea mayor a $40 \%$ y que, además, en la agrupación de municipios predomine la misma lengua. Aun cuando el criterio etnolingüístico forma parte de los criterios de distritación federal, también se aplicó en el ámbito local. 


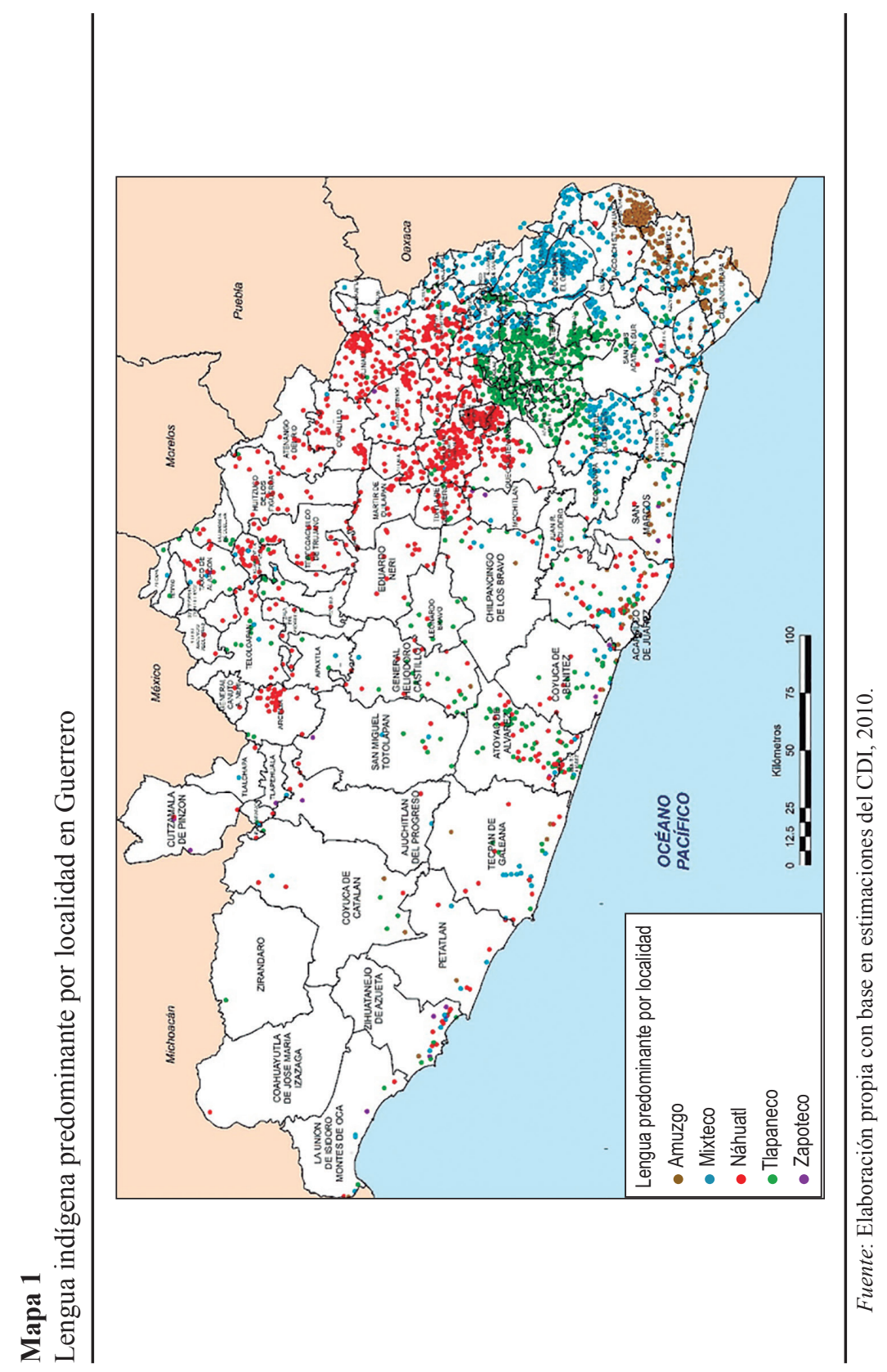


El presente artículo explica la metodología desarrollada para dar cumplimiento al criterio 3; sin embargo, para comprender el problema en su totalidad, se presenta un esquema con todos los criterios de distritación y su aplicación (véase el Esquema 1).

El criterio necesario para el desarrollo de la metodología que a continuación se explica es el 3, correspondiente a la agrupación de los pueblos indígenas, ${ }^{3}$ por lo que es importante conocer y aplicar los dos criterios previos:

Criterio 1. El número de distritos de la entidad federativa está señalado en la Constitución Estatal respectiva. La Constitución Política del Estado Libre y Soberano de Guerrero, en su artículo 29, indica que "El Congreso del Estado se compondrá por veintiocho Diputados de Mayoría Relativa, electos conforme al número de Distritos Locales [...]". Guerrero, por lo tanto, deberá dividirse en 28 circunscripciones uninominales.

Criterio 2. Para determinar el número de habitantes que tendrá cada distrito se utilizarán los resultados del Censo de Población y Vivienda 2010, publicados por el Instituto Nacional de Estadística y Geografía (INEGI) para la entidad federativa en cuestión y se dividirá a la población total entre el número de distritos a conformar. El resultado de este cociente será la población media estatal.

a) Se procurará que la población de cada distrito electoral sea lo más cercana a la población media estatal.

b) Se permitirá que la desviación poblacional de cada distrito con respecto a la población media estatal sea como máximo de $\pm 15 \%$. Cualquier excepción a esta regla deberá ser justificada.

De esta manera, la población total de Guerrero es de 3388768 habitantes; dividida entre 28 distritos electorales, el cociente señala una media estatal de 121027 habitantes. De manera ideal, la población de cada una de las circunscripciones deberá ser muy similar a esta cifra. Sin embargo, si se considera que la desviación poblacional de $\pm 15 \%$ es de 18154 habitantes, los distritos deberán contener un mínimo de 102873 y un máximo de 139182 habitantes.

${ }^{3}$ Para la distritación se definieron ocho criterios. Para evitar confundir al lector del presente documento, sólo se explican a detalle los criterios 1 a 3; el resto podrá consultarse en el Acuerdo del Consejo General INE/CG195/2015 (criterios de distritación local) y el Acuerdo INE/CG165/2016 (criterios de distritación federal). Para conocer los criterios de distritación local, consúltese http://ietam.org.mx/portal/documentos/Geografia/Antecedentes/3_Criterios. pdf, y para los criterios de distritación federal, véase http://www.dof.gob.mx/nota_detalle.php ? codigo $=5435486 \&$ fecha $=29 / 04 / 2016$ 


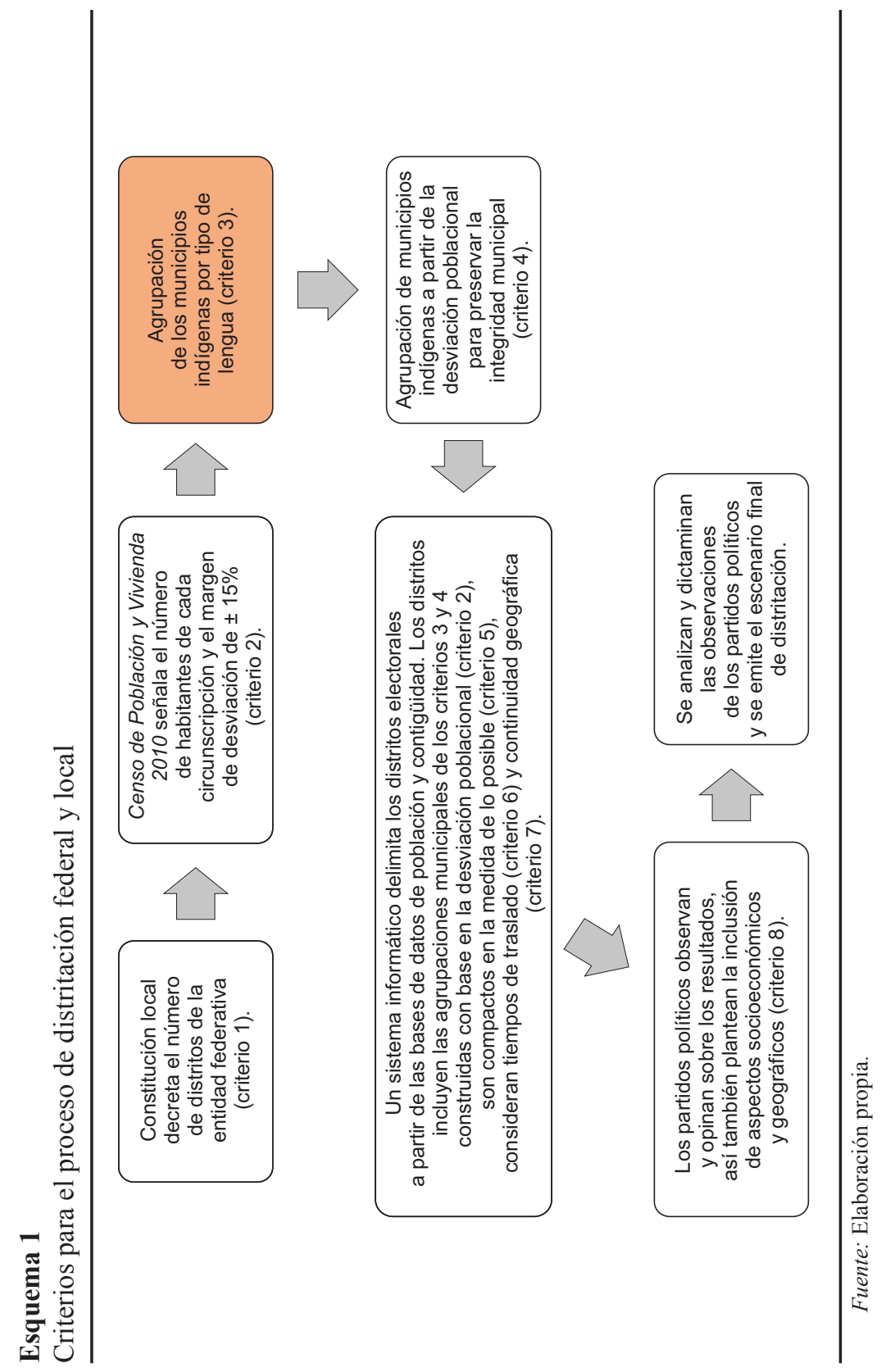


Una vez considerados los datos anteriores, el criterio 3 señala lo siguiente:

De acuerdo con la información provista y la definición establecida por la CDI, cuando sea factible, se conformarán los distritos con municipios que cuenten con $40 \%$ o más de población indígena y que, de ser posible, compartan la misma lengua predominante.

a) Los municipios con $40 \%$ o más de población indígena que sean colindantes entre sí serán agrupados; se preferirá integrar los municipios que compartan la misma lengua predominante.

b) Se sumará la población total de las agrupaciones anteriores. En caso de que la suma sea mayor a la población media estatal en más de $15 \%$, se dividirá la agrupación para integrar distritos dentro del margen permitido, procurando incorporar los municipios con mayor proporción de población indígena.

c) En el caso de que sea necesario integrar un municipio no indígena a la agrupación, se preferirá aquel con mayor proporción de población indígena.

d) En la conformación de estas agrupaciones, se consultará a las propias comunidades indígenas. La autoridad analizará la opinión y valorará su procedencia.

Para dar cumplimiento a este criterio, se diseñó la metodología que se detalla a continuación y que se esquematiza con el estado de Guerrero.

\section{Metodología para la agrupación de los municipios indígenas en las distritaciones}

El objetivo de esta metodología es diseñar las reglas para la incorporación de los pueblos indígenas en los trabajos de distritación.

Dos aspectos de fundamental importancia para desarrollar la presente metodología son, primero, definir los municipios indígenas y, segundo, determinar cómo se incorporará la lengua predominante en el momento de integrar los distritos; la CDI considera como municipio indígena a todo aquel que cuente con $40 \%$ o más de población en hogares indígenas, contabilizados en el Censo de Población y Vivienda 2010. Por otra parte, considerará como lengua predominante a aquella que suma el mayor número de hablantes dentro del municipio.

Los siguientes dos elementos a considerar son la proporción de la población media estatal con respecto a la población total de un municipio, y la 
proporción de la población media estatal de los grupos de municipios a integrarse. Las sumas de población de los agrupamientos de municipios indígenas no deberán exceder 139182 habitantes (población media estatal más 15 por ciento).

\section{Tipificación de municipios}

Para incorporar los municipios indígenas al sistema de distritación, se clasificarán y agruparán de la siguiente manera y de acuerdo con el porcentaje de población indígena, la lengua predominante y el número de habitantes.

Tipo 1. Municipios indígenas cuya proporción distrital está entre 0.85 y 1.15 constituyen un distrito electoral. En caso de que existan uno o más municipios vecinos con la misma lengua predominante y que agregados al primero se obtenga mejor equilibrio poblacional, se agruparán para formar un distrito.

Tipo 2. Municipios indígenas cuya proporción distrital permita construir dos o más distritos enteros en su interior, respetando el margen de desviación poblacional permitido.

Tipo 3. Municipios indígenas con más de 1.15 de proporción distrital que, agrupados con uno o más municipios indígenas vecinos con los que se comparta la lengua predominante, conformarán un número entero de distritos.

Tipo 4. Municipios indígenas excluidos de los tipos anteriores, en asociación con otro u otros municipios indígenas con la misma lengua predominante, podrán integrar los siguientes subtipos:

Tipo 4A. Agrupaciones de municipios indígenas con la misma lengua predominante y cuya proporción distrital se encuentre entre 0.85 y 1.15 , conformarán un distrito electoral.

Tipo 4B. Agrupaciones de municipios indígenas con la misma lengua predominante, cuya proporción distrital permita construir distritos enteros en su interior y dentro del margen poblacional permitido, conformarán el número de distritos correspondientes.

Invariablemente se incorporarán al sistema de distritación los municipios completos, a menos que una o más agrupaciones generen confinamientos. Se define como confinamiento al caso en el que uno o más municipios queden aislados en el momento de integrar una agrupación, o que una agrupación propicie que uno o más municipios queden sin la posibilidad de ser parte de un distrito. En el caso de que la aplicación de la tipología genere confina- 
miento, se seleccionará algún o algunos municipios para ser desagregados por secciones electorales y evitar la conformación de un distrito fuera del rango poblacional. Se fraccionará el menor número de municipios posible $\mathrm{y}$, en su caso, se fraccionará aquel o aquellos que al conformar distritos generen la menor desviación poblacional.

Tipo 4C. Agrupaciones de municipios indígenas con la misma lengua predominante cuya proporción distrital sea menor a 0.85 . Estas agrupaciones se unirán con otros municipios para conformar distritos dentro del rango poblacional.

Tipo 4D. Agrupaciones de municipios indígenas con la misma lengua predominante cuya proporción distrital sea mayor a 1.15. En éstas se separarán aquellos municipios ubicados en la periferia de la agrupación y se procurará conservar el grupo que presente la menor desviación poblacional. Los municipios excedentes, si son contiguos, deberán ser agrupados entre ellos.

Al tomar en cuenta la población total, la proporción de población indígena, las formas y la distribución de los municipios en las entidades federativas, se considerarán las siguientes salvedades:

a) Los municipios no indígenas, que queden confinados por agrupamientos de municipios indígenas, se integrarán al agrupamiento indígena con el que generen una menor desviación poblacional. Si es posible, se considerará la lengua predominante del municipio no indígena.

b) Los municipios o grupos de municipios indígenas confinados serán agrupados preferentemente con otros municipios o agrupaciones de municipios indígenas con los que se generen distritos dentro del rango de población permitido, procurando obtener la menor desviación poblacional posible.

c) En caso de existir municipios discontinuos, las fracciones deberán considerarse como municipios independientes.

En todos los casos se privilegia la opción con la menor desviación poblacional, así como la que favorezca la aplicación de los criterios y reglas operativas aprobados por el Consejo General del INE. 


\section{Agrupaciones de los municipios indígenas de Guerrero con base en su lengua predominante}

El estado de Guerrero está integrado por 81 municipios; de acuerdo con los criterios, los distritos se deben conformar por un territorio continuo. Cuatro municipios de la entidad se encuentran divididos en dos partes (Atlamajalcingo del Monte y San Luis Acatlán, ambos en sus fracciones Norte y Sur; Chilapa de Álvarez y Acatepec, uno y otro en sus fracciones Oriente y Poniente), por lo que estas fracciones se mencionarán de manera independiente a lo largo del texto.

Como ya se mencionó, para desarrollar la metodología antes planteada, deberán identificarse los municipios de la entidad que cuenten con más del $40 \%$ de población indígena, su lengua predominante, y calcular su proporción distrital (Cuadro 1 y Mapa 2).

El estado de Guerrero cuenta con 27 municipios con más de $40 \%$ de población indígena; sus lenguas predominantes son: amuzgo, mixteco, náhuatl y tlapaneco. De estos municipios, seis que tienen como lengua predominante el náhuatl son contiguos: Mártir de Cuilapan con 0.15, Zitlala con 0.18, Copalillo con 0.12 , Olinalá con 0.2 , Cualac con 0.06 y Tlapa de Comonfort con 0.67 de proporción distrital. José Joaquín de Herrera, con 0.13 de proporción distrital, en el que también predominan los hablantes de náhuatl, no forma parte de la contigüidad, por lo que no se incluye en el grupo. La suma de la población de los seis municipios equivale a 1.38 distritos electorales, lo que excede el rango máximo de población; otro aspecto a considerar es que confina los municipios no indígenas de Xochihuehuetlán, Huamuxtitlán, Alpoyeca y Tlalixtaquilla de Maldonado (Mapa 3).

De acuerdo con lo antes descrito, este conjunto es de tipo 4D (municipios con la misma lengua predominante cuya proporción distrital es mayor a 1.15). Lo anterior conlleva a las siguientes agrupaciones: los municipios de Tlapa de Comonfort, Olinalá y Cualac, con lengua predominante náhuatl, integran un conjunto al cual se suma la porción norte del municipio de Atlamajalcingo del Monte (aun cuando tiene como lengua predominante el tlapaneco), debido a que se encuentra en el interior de Tlapa de Comonfort. Finalmente, se suman los municipios Xochihuehuetlán y Huamuxtitlán (que tienen como lengua predominante el náhuatl), los cuales no tienen la proporción de población para ser considerados como indígenas, pero quedan confinados (Cuadro 2, Mapa 4). La suma de la población de los seis municipios equivale a 1.11 de la proporción distrital, por lo que integra un distrito electoral. 


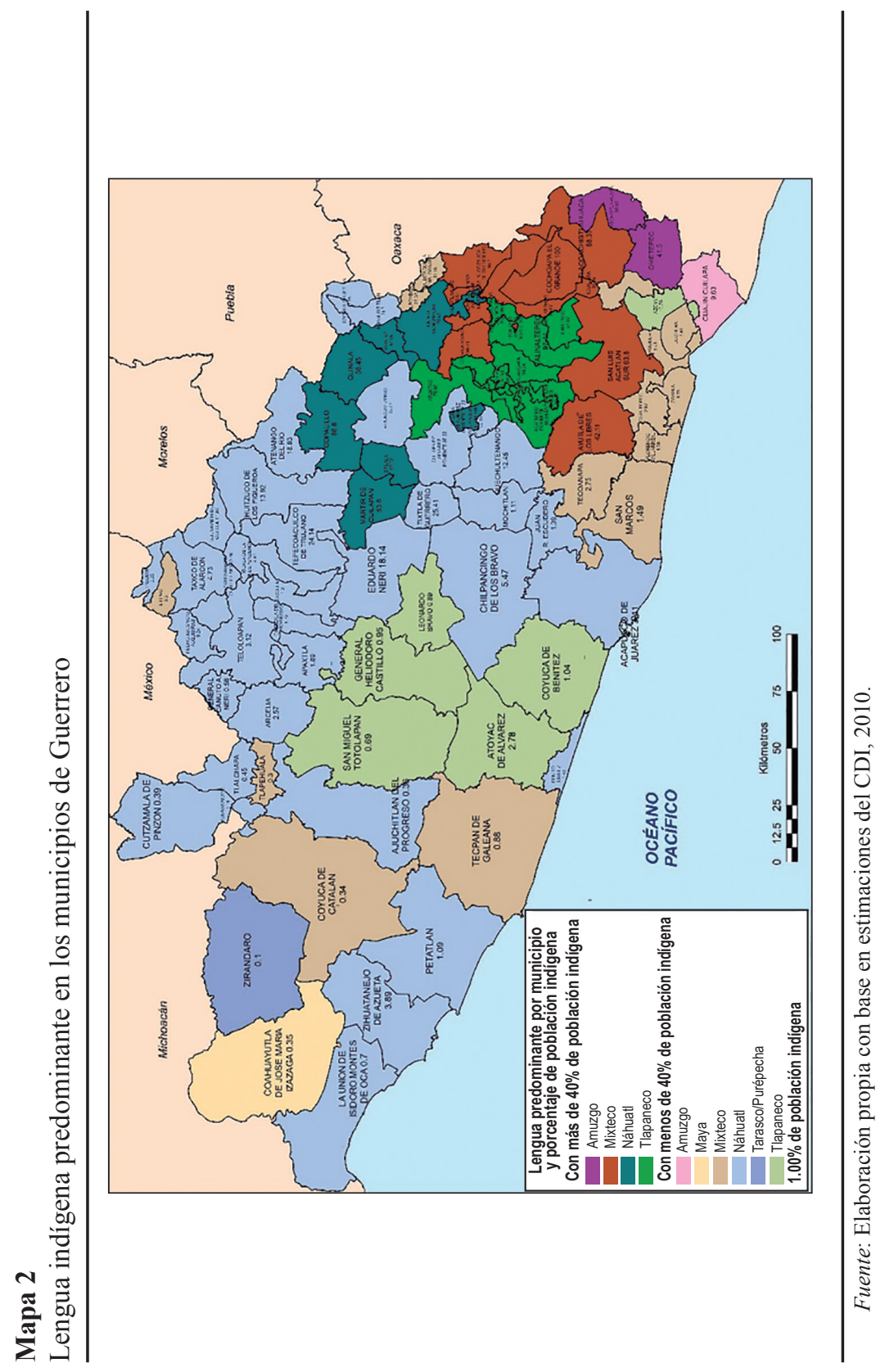




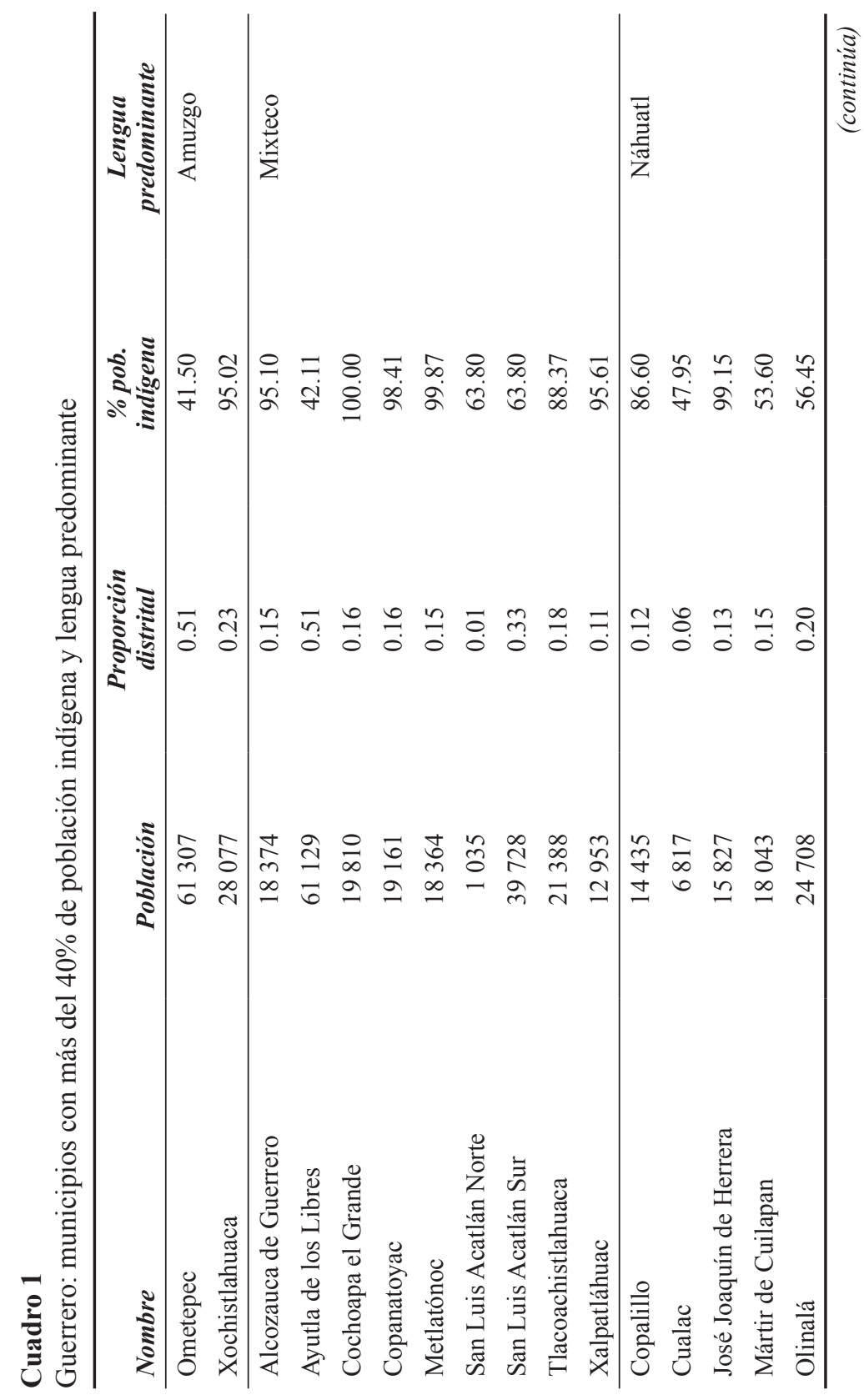




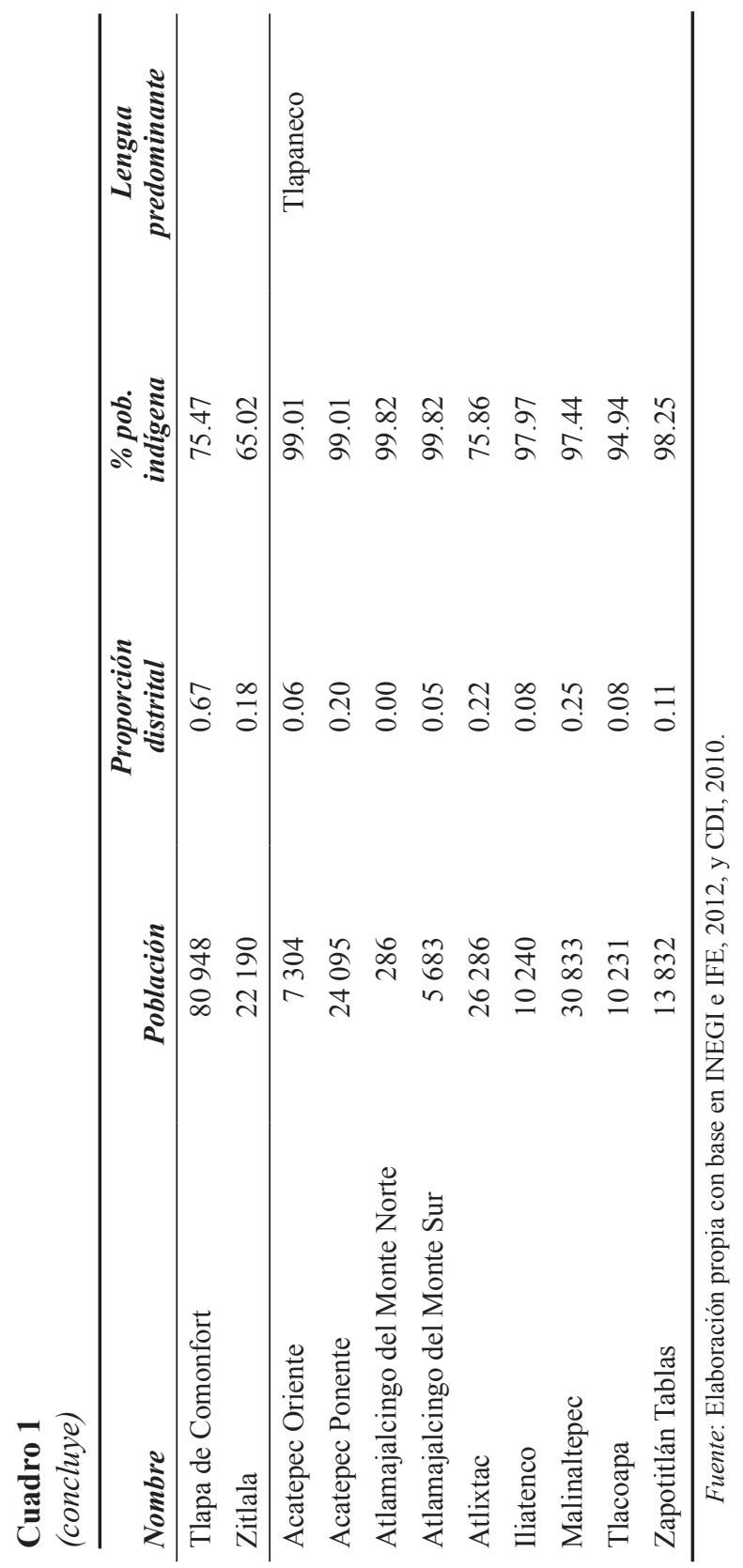




\section{Mapa 3}

Municipios con más del $40 \%$ de población indígena

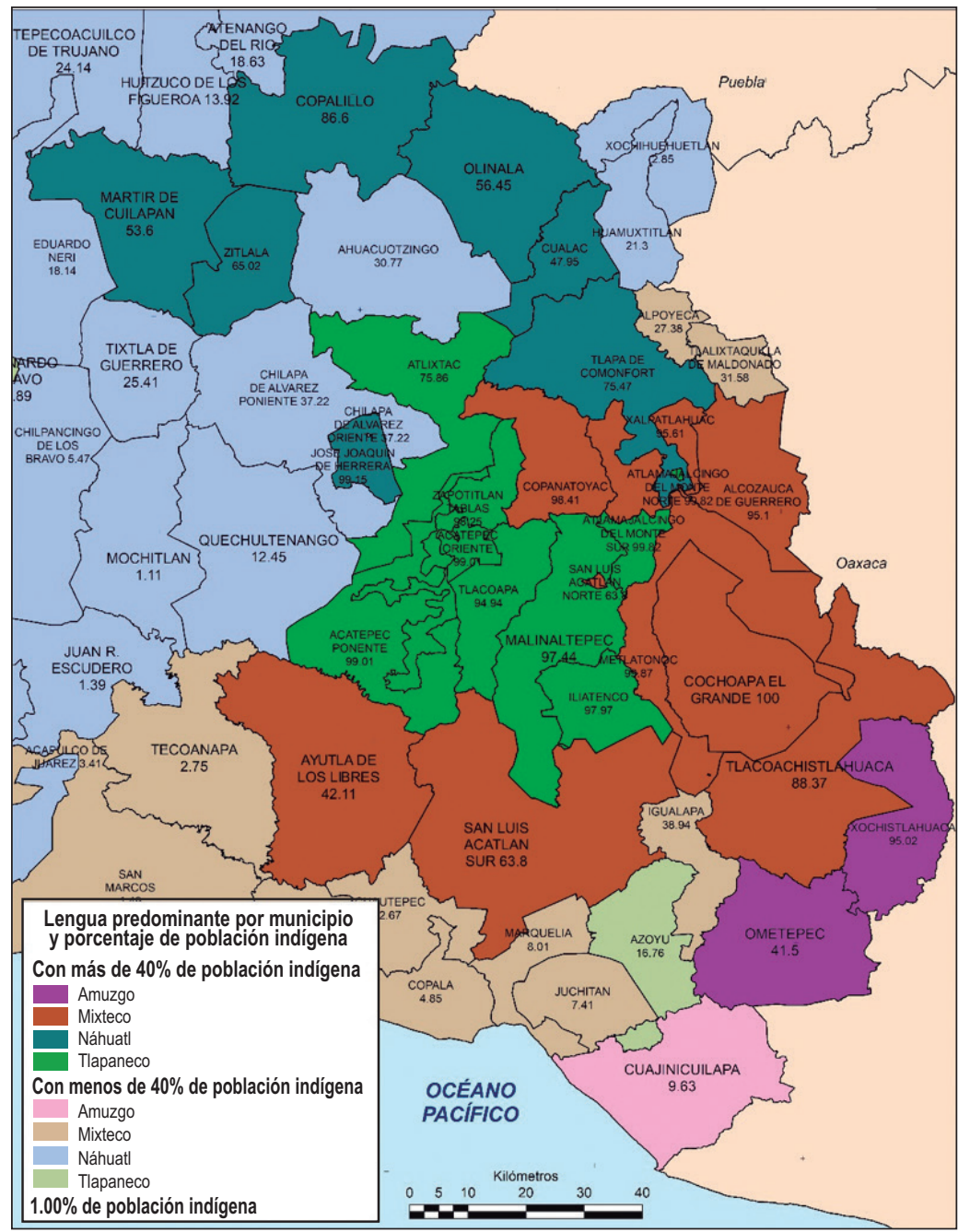

Fuente: Elaboración propia con base en estimaciones del CDI, 2010. 


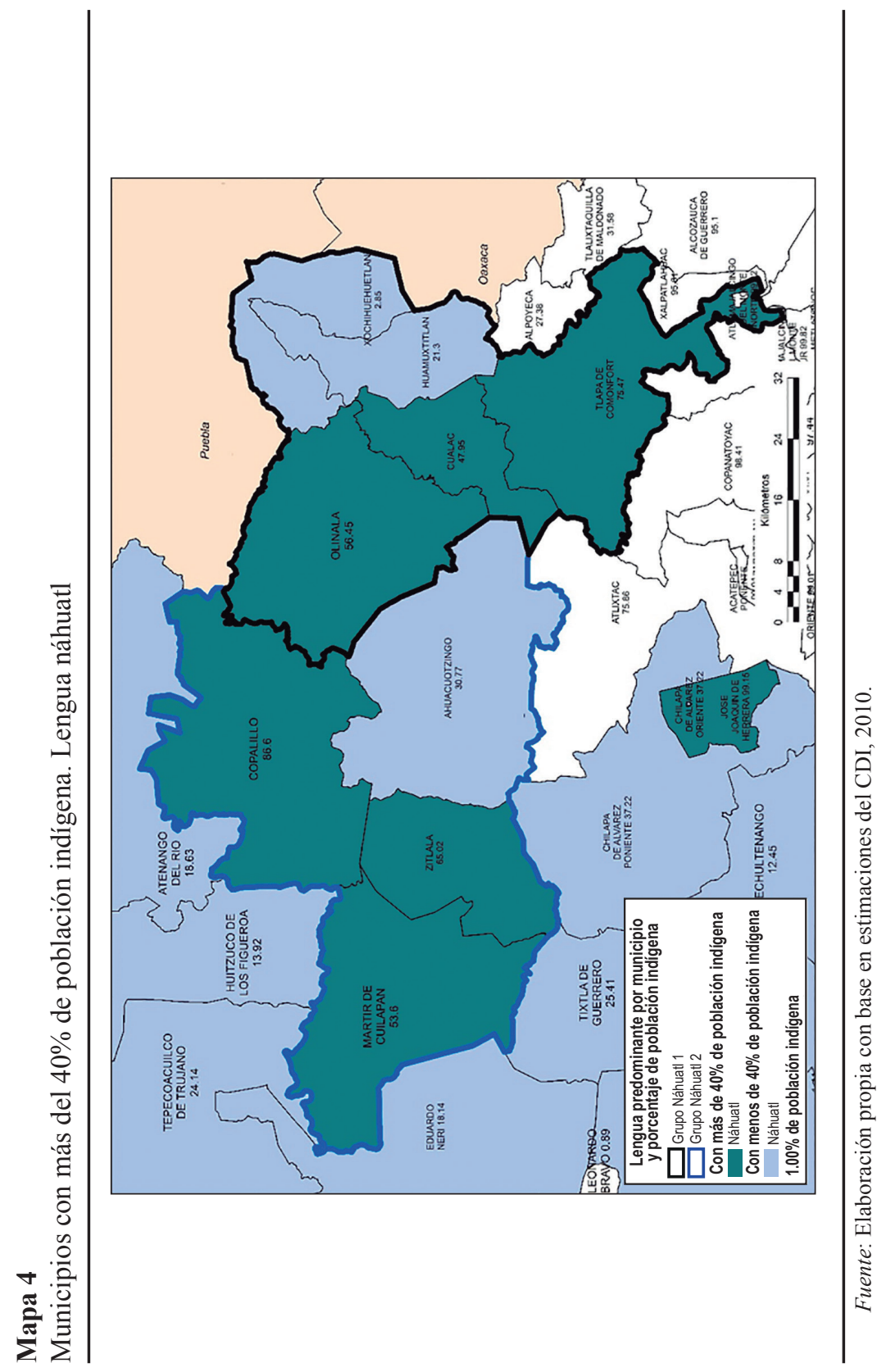




\section{Cuadro 2}

Municipios con más del $40 \%$ de población indígena y predominancia de lengua náhuatl. Primer grupo

\begin{tabular}{lcccc}
\hline Municipio & $\begin{array}{c}\text { Población } \\
\text { total }\end{array}$ & $\begin{array}{c}\text { Proporción } \\
\text { pob. } \\
\text { indígena }\end{array}$ & $\begin{array}{c}\text { Proporción } \\
\text { distrital }\end{array}$ & $\begin{array}{c}\text { Lengua } \\
\text { predominante }\end{array}$ \\
\hline Tlapa de Comonfort & 80948 & 75.47 & 0.67 & Náhuatl \\
Olinalá & 24708 & 56.45 & 0.2 & \\
Cualac & 6817 & 47.95 & 0.06 & \\
$\begin{array}{l}\text { Por confinamiento } \\
\text { Huamuxtitlán }\end{array}$ & 14583 & 21.3 & 0.12 & Náhuatl \\
$\begin{array}{l}\text { Xochihuehuetlán } \\
\text { Atlamajalcingo } \\
\text { del Monte Norte }\end{array}$ & 7079 & 2.85 & 0.06 & Tlapaneco \\
Total & 286 & 99.82 & 0 & \\
\hline
\end{tabular}

Fuente: Elaboración propia con base en INEGI e IFE, 2012, y CDI, 2010.

El segundo grupo con predominancia de lengua náhuatl incluye los municipios Mártir de Cuilapan, Zitlala y Copalillo. La población de los tres suma una proporción distrital de 0.45 (Cuadro 3); a este grupo se incorpora el municipio de Ahuacuotzingo ( 0.21 de proporción distrital) debido a que al oriente colinda con una agrupación definida ya como un distrito electoral y al sur se confina por un conjunto de municipios tlapanecos (Mapa 4). La suma de la población de los cuatro municipios es de 0.66 de proporción distrital, insuficiente para integrar un distrito.

De los nueve municipios indígenas con lengua predominante mixteca, ocho son contiguos: Ayutla de los Libres con 0.51, San Luis Acatlán Sur con 0.33 , Tlacochistlahuaca con 0.18, Alcozauca de Guerrero con 0.15, Xalpatláhuac con 0.11 , Copanatoyac con 0.16 , Metlatónoc con 0.15 y Cochoapa el Grande con 0.16 de proporción distrital; la población de todos suma 1.75. Esta proporción distrital permite la construcción de dos distritos electorales, cada uno de ellos con una proporción distrital aproximada de 0.875 ; pero la desviación poblacional, aunque es aceptada, sería muy elevada y probablemente tendría que fraccionarse algún municipio para que los distritos quedaran dentro del rango poblacional. Por tanto, y para favorecer una desviación poblacional cercana a cero, ésta agrupación es considerada de tipo 4D (agrupaciones de municipios indígenas con la misma lengua predominante, 


\section{Cuadro 3}

Municipios con más del 40\% de población indígena y predominancia de lengua náhuatl. Segundo grupo

\begin{tabular}{lcccc}
\hline Municipio & $\begin{array}{c}\text { Población } \\
\text { total }\end{array}$ & $\begin{array}{c}\text { Proporción } \\
\text { pob. } \\
\text { indígena }\end{array}$ & $\begin{array}{c}\text { Proporción } \\
\text { distrital }\end{array}$ & $\begin{array}{c}\text { Lengua } \\
\text { predominante }\end{array}$ \\
\hline Copalillo & 14435 & 86.6 & 0.12 & Náhuatl \\
Zitlala & 22190 & 65.02 & 0.18 & \\
Mártir de Cuilapan & 18043 & 53.6 & 0.15 & \\
Por confinamiento & & & & \\
Ahuacuotzingo & 25015 & 30.77 & 0.21 & Náhuatl \\
& & & & \\
Total & 79683 & & 0.66 & \\
\hline
\end{tabular}

Fuente: Elaboración propia con base en INEGI e IFE, 2012 y CDI, 2010.

cuya proporción distrital sea mayor a 1.15). En este caso, se conformará un distrito y se separarán aquellos municipios ubicados en la periferia de la agrupación, procurando conservar el grupo que presente la menor desviación poblacional. Los municipios excedentes, si son contiguos, deberán ser agrupados entre ellos. El municipio de San Luis Acatlán Norte es discontinuo al grupo, por lo que no se integrará.

De esta manera, se agrupan los municipios contiguos de Cochoapa el Grande, Metlatónoc, Copanatoyac, Xalpatláhuac, Alcozauca de Guerrero y Tlacoachistlahuaca; debido al confinamiento en la parte norte también se añaden Tlalixtaquilla de Maldonado y Alpoyeca, que tienen como lengua predominante el mixteco y no cuentan con la proporción de población establecida para considerarse como indígenas. Además, también será incluido Igualapa, ya que cuenta con una fracción de sección discontinua en el interior de Metlatónoc, y con su incorporación se preserva el criterio de continuidad geográfica. La suma de los nueve municipios suma una proporción distrital de 1.12, por lo que conformará un distrito electoral (Cuadro 4 y Mapa 5).

Un segundo agrupamiento mixteco considera a los municipios de San Luis Acatlán Sur y Ayutla de los Libres. La población de ambos suma 0.84 de proporción distrital, lo cual no es suficiente para conformar un distrito electoral y se constituye como un grupo de tipo $4 \mathrm{C}$, por lo que ingresará al sistema y en conjunto con otros municipios conformará un distrito dentro del rango poblacional establecido (Cuadro 5 y Mapa 5). 


\section{Cuadro 4}

Agrupación de municipios con más del 40\% de población indígena y predominancia de lengua mixteca. Tercer agrupamiento

\begin{tabular}{|c|c|c|c|c|}
\hline Municipio & $\begin{array}{c}\text { Población } \\
\text { total }\end{array}$ & $\begin{array}{c}\text { Proporción } \\
\text { pob. } \\
\text { indígena }\end{array}$ & $\begin{array}{c}\text { Proporción } \\
\text { distrital }\end{array}$ & $\begin{array}{c}\text { Lengua } \\
\text { predominante }\end{array}$ \\
\hline Cochoapa el Grande & 19810 & 100 & 0.16 & Mixteco \\
\hline Metlatónoc & 18364 & 99.87 & 0.15 & \\
\hline Copanatoyac & 19161 & 98.41 & 0.16 & \\
\hline Xalpatláhuac & 12953 & 95.61 & 0.11 & \\
\hline Alcozauca de Guerrero & 18374 & 95.1 & 0.15 & \\
\hline Tlacoachistlahuaca & 21388 & 88.37 & 0.18 & \\
\hline \multicolumn{5}{|l|}{ Por confinamiento } \\
\hline $\begin{array}{l}\text { Tlalixtaquilla de } \\
\text { Maldonado }\end{array}$ & 6679 & 31.58 & 0.06 & Mixteco \\
\hline Alpoyeca & 7054 & 27.38 & 0.06 & \\
\hline \multicolumn{5}{|l|}{$\begin{array}{l}\text { Por integridad } \\
\text { municipal }\end{array}$} \\
\hline Igualapa & 10555 & 38.94 & 0.09 & Mixteco \\
\hline Total & 134338 & & 1.12 & \\
\hline
\end{tabular}

Fuente: Elaboración propia con base en INEGI e IFE, 2012 y CDI, 2010.

\section{Cuadro 5}

Agrupación de municipios con más del $40 \%$ de población indígena y predominancia de lengua mixteca. Cuarto agrupamiento

\begin{tabular}{lcccc}
\hline & $\begin{array}{c}\text { Población } \\
\text { total }\end{array}$ & $\begin{array}{c}\text { Proporción } \\
\text { pob. } \\
\text { indígena }\end{array}$ & $\begin{array}{c}\text { Proporción } \\
\text { distrital }\end{array}$ & $\begin{array}{c}\text { Lengua } \\
\text { predominante }\end{array}$ \\
\hline San Luis Acatlán Sur & 39728 & 63.8 & 0.33 & Mixteco \\
Ayutla de los Libres & 61129 & 42.11 & 0.51 & \\
Total & 100857 & & 0.84 & \\
\hline
\end{tabular}

Fuente: Elaboración propia con base en INEGI e IFE, 2012 y CDI, 2010. 


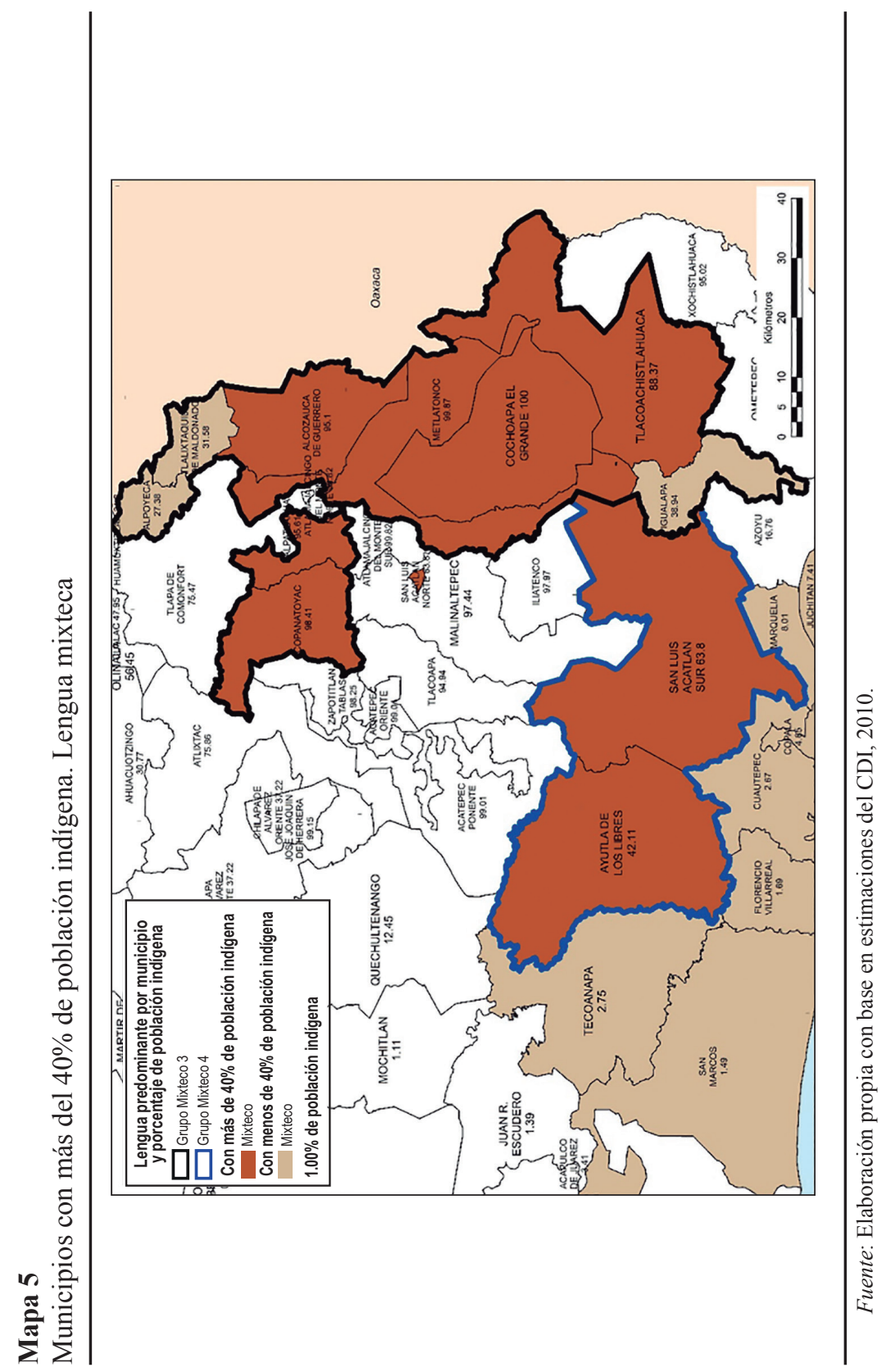


De los nueve municipios con más del $40 \%$ de población indígena que tienen como lengua predominante el tlapaneco, ocho de ellos son contiguos: Acatepec Oriente con 0.06, Acatepec Poniente con 0.2, Atlamajalcingo del Monte Sur con 0.05, Atlixtac con 0.22, Iliatenco con 0.08, Malinaltepec con 0.25 , Tlacoapa con 0.08 , y Zapotitlán Tablas con 0.11 de proporción distrital. La suma de sus poblaciones equivale a 1.05 de proporción distrital, por lo que se encuentra en el rango de población para conformar un distrito electoral, y es de tipo 4A. Sin embargo, también se incluye a San Luis Acatlán Norte, que tiene predominancia de lengua mixteca, pero se encuentra confinado en el interior de Malinaltepec. La suma del conjunto de municipios es de 1.06 de proporción distrital, suficiente para conformar un distrito electoral (Cuadro 6 y Mapa 6).

Finalmente, los municipios indígenas de Xochistlahuaca con 0.23 y Ometepec con 0.51 de proporción distrital ( 0.74 en total), que tienen como lengua predominante el amuzgo, forman un grupo de tipo $4 \mathrm{C}$ (Cuadro $7 \mathrm{y}$ Mapa 7).

\section{Cuadro 6}

Municipios con más del $40 \%$ de población indígena y predominancia de lengua tlapaneca. Grupo cinco

\begin{tabular}{lrccc}
\hline & $\begin{array}{c}\text { Población } \\
\text { total }\end{array}$ & $\begin{array}{c}\text { Proporción } \\
\text { pob. } \\
\text { indígena }\end{array}$ & $\begin{array}{c}\text { Proporción } \\
\text { distrital }\end{array}$ & $\begin{array}{c}\text { Lengua } \\
\text { predominante }\end{array}$ \\
\hline Municipio & 5683 & 99.82 & 0.05 & Tlapaneco \\
$\quad$ Monte Sur & 24095 & 99.01 & 0.2 & \\
Acatepec Poniente & 7304 & 99.01 & 0.06 & \\
Acatepec Oriente & 13832 & 98.25 & 0.11 & \\
Zapotitlán Tablas & 10240 & 97.97 & 0.08 & \\
Iliatenco & 30833 & 97.44 & 0.25 & \\
Malinaltepec & 10231 & 94.94 & 0.08 & \\
Tlacoapa & 26286 & 75.86 & 0.22 & \\
Atlixtac & & & & \\
& & & & \\
Por confinamiento & 1035 & 63.8 & 0.01 & Mixteco \\
San Luis Acatlán Norte & 129539 & & 1.06 & \\
Total & & & & \\
\hline
\end{tabular}

Fuente: Elaboración propia con base en INEGI e IFE, 2012 y CDI, 2010. 


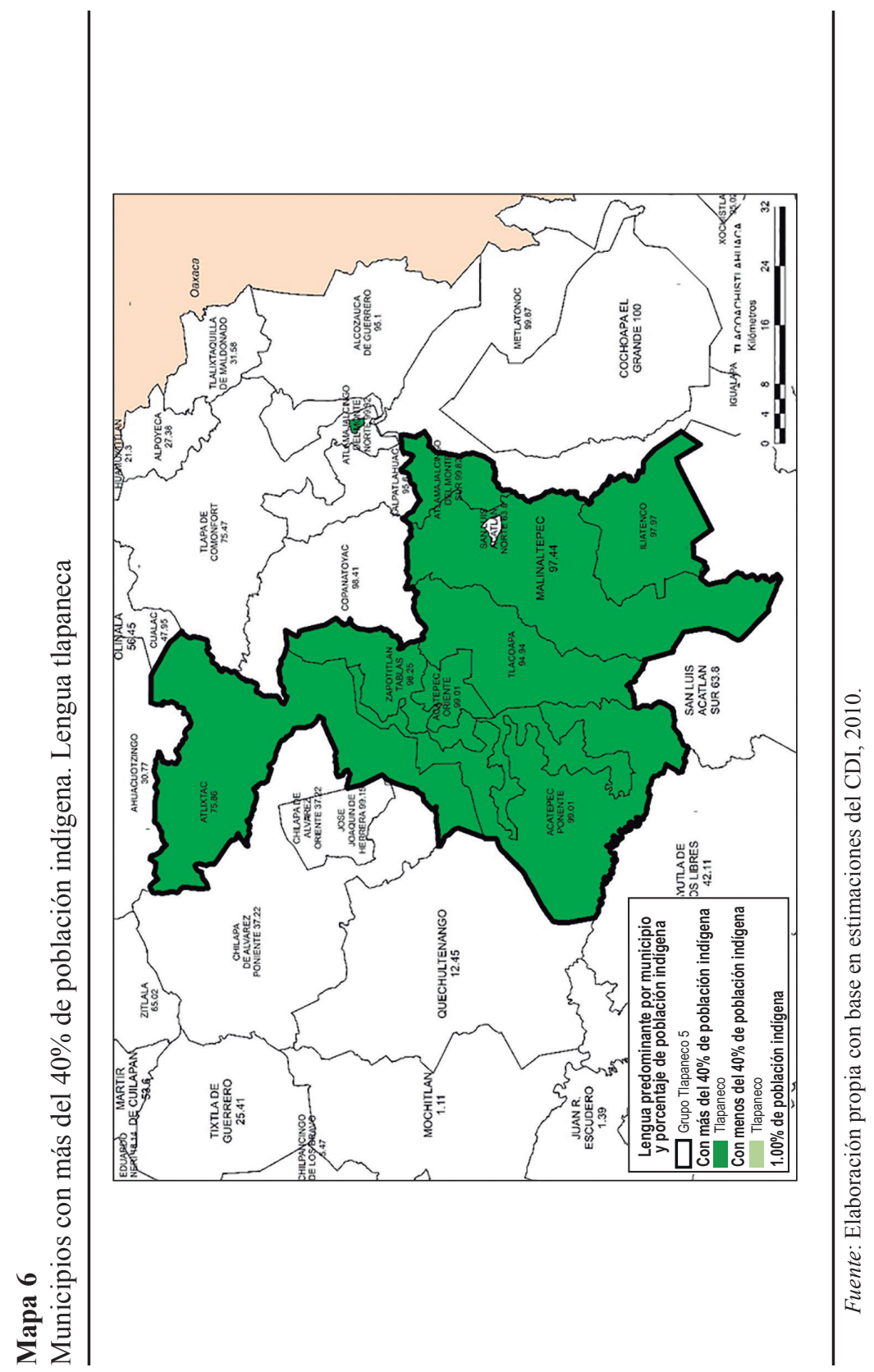




\section{Cuadro 7}

Agrupación de municipios con más del $40 \%$ de población indígena y predominancia de lengua amuzga. Sexto agrupamiento

\begin{tabular}{lcccc}
\hline Municipio & $\begin{array}{c}\text { Población } \\
\text { total }\end{array}$ & $\begin{array}{c}\text { Proporción } \\
\text { pob. } \\
\text { indígena }\end{array}$ & $\begin{array}{c}\text { Proporción } \\
\text { distrital }\end{array}$ & $\begin{array}{c}\text { Lengua } \\
\text { predominante }\end{array}$ \\
\hline Xochistlahuaca & 28077 & 95.02 & 0.23 & Amuzgo \\
Ometepec & 61307 & 41.5 & 0.51 & \\
Total & 89384 & & 0.74 & \\
\hline
\end{tabular}

Fuente: Elaboración propia con base en INEGI e IFE, 2012, y CDI, 2010.

$\mathrm{Al}$ considerar los municipios con más del $40 \%$ de población indígena y su lengua predominante se demarcaron seis regiones, tres de ellas integran distritos con identidad mayoritaria de los grupos etnolingüísticos náhuatl, mixteco y tlapaneco. Adicionalmente, se conformaron tres regiones que no cuentan con la población suficiente para conformar un distrito electoral; por lo tanto, éstas se sumarán a otros municipios para conformar distritos dentro del rango poblacional establecido.

Las seis agrupaciones incluyen a 32 de los 85 municipios que conforman al estado de Guerrero (Cuadro 8 y Mapa 8).

\section{Cuadro 8}

Agrupaciones de municipios indígenas en el estado de Guerrero

\begin{tabular}{lccc}
\hline Caso & $\begin{array}{c}\text { Lengua } \\
\text { predominante }\end{array}$ & $\begin{array}{c}\text { Proporción } \\
\text { distrital }\end{array}$ & $\begin{array}{c}\text { Municipios } \\
\text { incorporados }\end{array}$ \\
\hline 1 & Náhuatl & 1.11 & 6 \\
2 & Náhuatl & 0.66 & 4 \\
3 & Mixteco & 1.12 & 9 \\
4 & Mixteco & 0.84 & 2 \\
5 & Tlapaneco & 1.06 & 9 \\
6 & Amuzgo & 0.74 & 2 \\
Total & & & 32 \\
\hline
\end{tabular}

Fuente: Elaboración propia con base en INEGI e IFE, 2012 y CDI, 2010. 


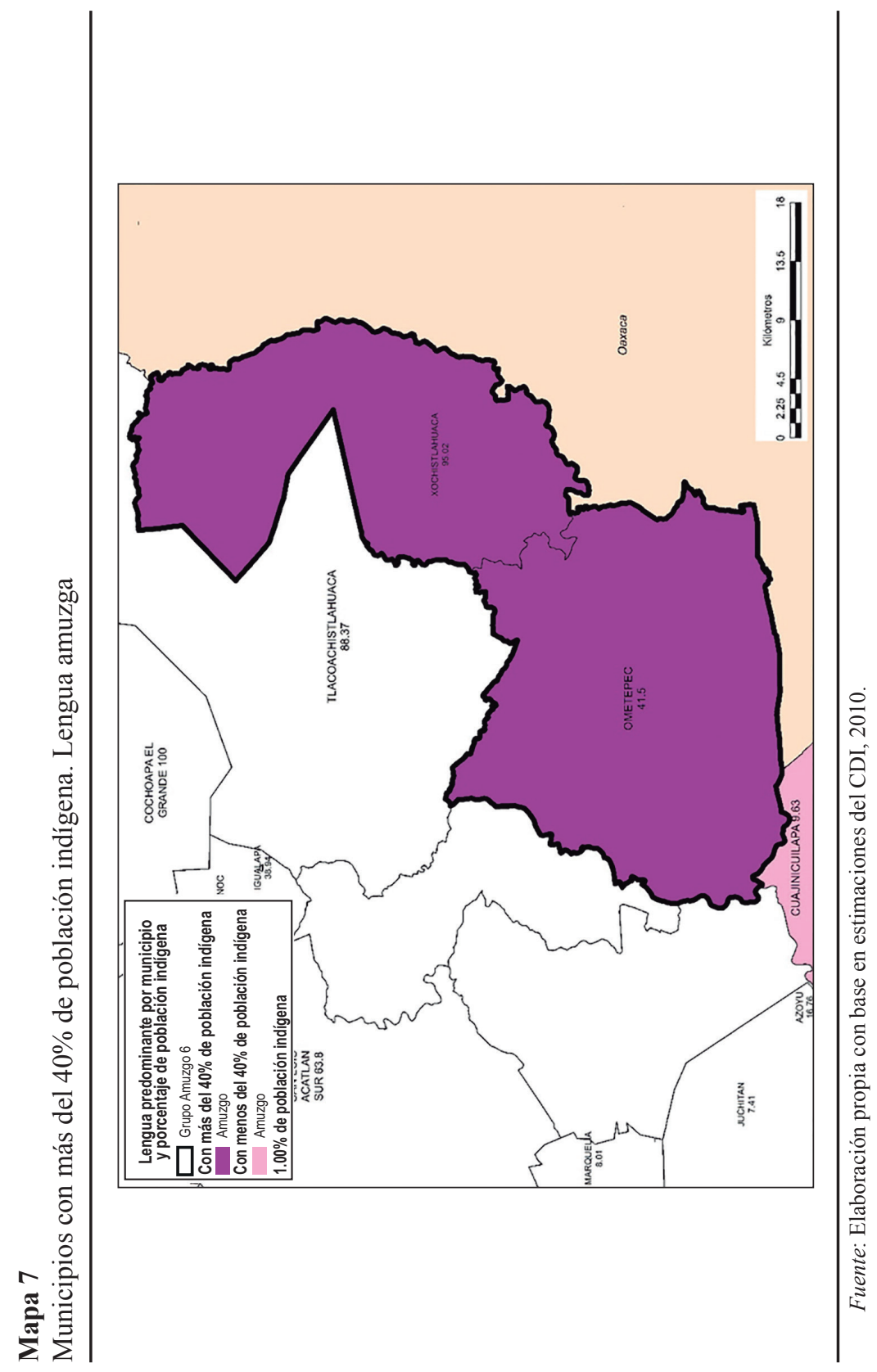




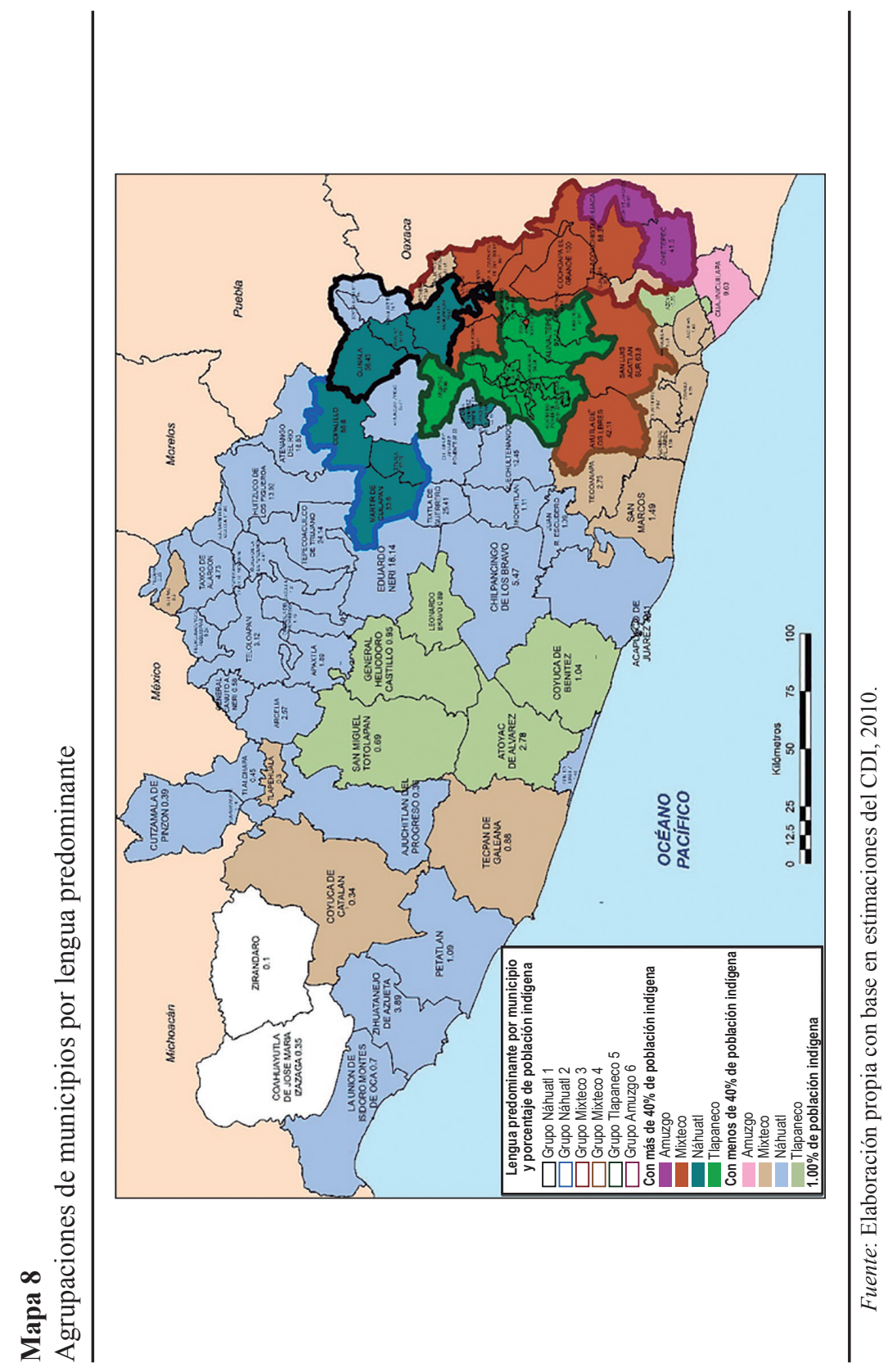




\section{Conclusiones}

El proyecto de distritación llevado a cabo por el INE en el periodo 2015-2017, y del cual formó parte la metodología aquí explicada, se basó en un conjunto de criterios y reglas que permitieron demarcar regiones homogéneas en cuanto a su población total y que a la vez diferencian e integran a los grupos indígenas mediante su lengua.

El desarrollo metodológico se consolidó en una caracterización de grupos de municipios, cada uno de ellos a partir de su ubicación dentro de la entidad federativa, su forma y sus vecindades. A lo anterior se aunó su población total, así como también los habitantes indígenas diferenciados por sus diferentes lenguas. El ejercicio aplicado al estado de Guerrero permitió poner a la vista la complejidad de la geografía política a partir la perspectiva de la integración regional: desde la discontinuidad de los territorios municipales, las irregulares formas de la geografía política municipal, la distribución de la población y, sobre todo, la configuración de los territorios con alta presencia de población indígena, así como la mezcla de sus lenguas en la geografía del estado.

La demarcación distrital es un ejercicio que integra tanto aspectos técnicos como políticos. Aun cuando se precisaron criterios con rigurosidad demográfica, geográfica y matemática, uno de ellos se definió desde la perspectiva eminentemente política, el cual consiste en un acuerdo de todos los partidos políticos, tanto locales como federales. De las 24 entidades federativas en las que se aplicó la metodología aquí explicada, Guerrero fue la única que mediante un acuerdo muy particular de todas las fuerzas políticas logró que no se aplicara y prevaleció la distritación vigente en ese momento, en la que no se cumplió con la integración de las lenguas y que mostraba una gran cantidad de municipios fraccionados en diferentes distritos electorales. No obstante lo anterior, el ejercicio permite explicar la complejidad territorial que implica la aplicación de criterios demográficos, geográficos y etnolingüísticos en la demarcación de regiones políticas.

La integración de distritos electorales en los que se distinguen las regiones con mayor concentración de población indígena y en las que se buscó que preferentemente compartieran la misma lengua, tiene gran relevancia y constituye un significativo avance democrático en cuanto a la representación político-electoral de un grupo social particular, que busca formar parte de la representación ante los órganos legislativos tanto locales como federales. 


\section{Bibliografía}

Baños, M. A. y Palacios, C. (2014). Evolución territorial de los distritos electorales federales uninominales, 1977-2010. Investigaciones Geográficas. Boletín del Instituto de Geografía, 84, 81-95. Recuperado de http://www.scielo.org.mx/pdf/igeo/n84/n84a8.pdf

Constitución Política de los Estados Unidos Mexicanos. (2018). Artículo Tercero Transitorio. México: H. Congreso de la Unión.

Constitución Política del Estado Libre y Soberano de Guerrero. (2018). Chilpancingo: Gobierno del Estado de Guerrero.

CDI (Comisión Nacional para el Desarrollo de los Pueblos Indígenas). (2006). Regiones indígenas de México. Ciudad de México: Comisión Nacional para el Desarrollo de los Pueblos Indígenas / Programa de las Naciones Unidas para el Desarrollo.

CDI (Comisión Nacional para el Desarrollo de los Pueblos Indígenas). (2010). Población indígena por municipio y grupo etnolingüístico, con base en el Censo de Población y Vivienda 2010. Ciudad de México: Comisión Nacional para el Desarrollo de los Pueblos Indígenas.

CDI (Comisión Nacional para el Desarrollo de los Pueblos Indígenas). (2017). Indicadores de la población indígena. Ciudad de México: Comisión Nacional para el Desarrollo de los Pueblos Indígenas. Recuperado de https://www.gob.mx/cdi/documentos/indicadores-de-la-po blacion-indigena

INEGI. (2010). Síntesis metodológica y conceptual del Censo de Población y Vivienda 2010. Ciudad de México: Instituto Nacional de Estadística y Geografía.

INEGI e IFE. (2012). Estadísticas censales a escalas geoelectorales. Censo de Población y Vivienda 2010 [en línea]. Ciudad de México: Instituto Nacional de Estadística y Geografía / Instituto Federal Electoral. Recuperado de http://gaia.inegi.org.mx/geoelectoral/viewer.html\#

Instituto Nacional Electoral. (2015). Acuerdo del Consejo General del Instituto Nacional Electoral, por el que se aprueban los criterios y reglas operativas que deberán aplicarse para el análisis y la delimitación territorial de los distritos en las entidades federativas, previo a sus respectivos procesos electorales locales. Acuerdo INE/CG195/2015 [en línea]. Ciudad de México: Instituto Nacional Electoral. Recuperado de http://ietam.org.mx/portal/documentos/Geografia/Antecedentes/3_Cri terios.pdf [fecha de consulta: 22 de marzo de 2017].

Instituto Nacional Electoral. (2017). ¿Qué es la cartografía electoral? [en línea]. Ciudad de México: Instituto Nacional Electoral. Recuperado de 
http://cartografia.ife.org.mx/sige7/?inicio [fecha de consulta: $28 \mathrm{de}$ marzo de 2017].

\section{Acerca de las autoras}

Celia Palacios Mora es doctora en Geografía por la Universidad Nacional Autónoma de México (UNAM), institución en la que se desempeña como profesora del Posgrado y del Colegio de Geografía. Es perito de la Suprema Corte de Justicia de la Nación en materia de geografía y cartografía. Ha coordinado coloquios y diplomados internacionales de geografía electoral. Formó parte de los Comités Técnicos Científicos para Evaluar el Padrón Electoral, elecciones de 2008-2009 y 2011-2012; así como del Comité Técnico para Evaluar los Materiales Electorales 2008-2009 y de los Comités Técnicos de Distritación 2012-2013 y 2015-2017. Cuenta con publicaciones en revistas científicas en temas como: voto desde el extranjero, circunscripciones electorales, ubicación óptima de módulos electorales y padrón electoral mexicano.

Leticia Gerónimo Mendoza es licenciada en Geografía por la Universidad Nacional Autónoma de México. Ha colaborado en distintos proyectos de distritación federales y locales en temas de geografía y cartografía. Ha fungido como asesora en estudios de impacto social en materia geográfica para proyectos de instalación de plantas automotrices, gasoductos e hidroeléctricas. Asimismo, ha participado en la coordinación de proyectos de desarrollo social en el ámbito público y en la esfera electoral.

Recepción: 1 de marzo de 2018.

Aceptación: 21 de mayo de 2018. 
